\title{
CLINICAL OUTCOMES AFTER UNICOMPARTMENTAL KNEE ARTHROPLASTY FOR OSTEONECROSIS OF THE KNEE
}

\author{
DESFECHOS CLIINIICOS APÓS ARTROPLASTIA \\ UNICOMPARTIMENTAL DO JOELHO NO \\ TRATAMENTO DA OSTEONECROSE DO JOELHO
}

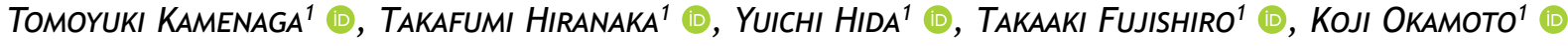

1. Takatsuki General Hospital, Department of Orthopedic Surgery and Joint Surgery Center, Takatsuki, Osaka, Japan.

\section{ABSTRACT}

Objective: Although the mobile-bearing Oxford unicompartmental knee arthroplasty (OUKA) seems an appropriate procedure to treat spontaneous osteonecrosis of the knee (SONK), aseptic tibial component loosening was the leading cause for medial UKA failure. This study aimed to observe short-term and midterm clinical outcomes following OUKA and determine whether tibial lesion affects the procedure clinical and radiographic outcomes. Methods: Sixty patients (mean age $73.1 \pm 6.6$ years) diagnosed with SONK in the medial femoral condyle and treated with OUKA were separated into two groups using T1-weighted preoperative magnetic resonance imaging (MRI): group F (necrotic lesion confined to the femur) and group T (necrotic lesion spread to the tibia). The Oxford Knee Score (OKS), maximum flexion angle (MFA), and radiographic findings (radiolucent line and subsidence) were compared between the two groups using unpaired $t$-test. Results: Both groups showed significant improvement in OKS and MFA values at the final follow-up, but without significant differences in the clinical and radiographic outcomes. Conclusion: OUKA is a reliable treatment procedure for SONK in the short and midterm. The presence of tibial lesions on preoperative MRI does not affect postoperative radiographic and clinical outcomes. Level of Evidence IV, Case Series.

Keywords: Knee. Arthroplasty. Osteonecrosis.

\section{RESUMO}

Objetivo: Embora a Artroplastia Unicompartimental do Joelho (AUJ) de Oxford pareça ser um procedimento adequado para o tratamento da Osteonecrose Espontânea do Joelho (ONEJ), o afrouxamento asséptico do componente tibial foi a principal causa de fracassos na AUJ medial. Este estudo teve por objetivo observar desfechos clínicos de curto e médio prazo após AUJ, além de determinar se a presença de lesão tibial interfere nos desfechos clínicos e radiográficos do procedimento. Métodos: Sessenta pacientes (idade média de $73,1 \pm 6.6$ anos) diagnosticados com ONEJ no côndilo medial do fêmur e tratados com AUJ foram divididos em dois grupos por meio de imagens ponderadas em T1 obtidas em exames pré-operatórios de ressonância magnética (RM): grupo F (lesão necrótica limitada ao fêmur) e grupo $T$ (lesão necrótica espalhada para a tíbia). Os valores obtidos no Oxford Knee Score (OKS) e o ângulo de flexão máxima (AFM), bem como achados radiográficos (linha radiotransparente e subsidência) para cada grupo foram comparados usando teste $t$ não-pareado. Resultados: Ambos os grupos apresentaram melhoria significativa nos valores de OKS e AFM no último acompanhamento, mas sem diferenças significativas nos desfechos clínicos e radiográficos. Conclusão: AUJ é um procedimento confiável para o tratamento de ONEJ a curto e médio prazo. A presença de lesões da tíbia, diagnosticada por meio da RM pré-operatória, não afetou os desfechos clínicos e radiográficos no pós-operatório. Nível de Evidência IV, Série de casos.

Descritores: Joelho. Artroplastia. Osteonecrose.

Citation: Kamenaga T, Hiranaka T, Hida Y, Fujishiro T, Okamoto K. Clinical outcomes after unicompartmental knee arthroplasty for osteonecrosis of the knee. Acta Ortop Bras. [online]. 2021;29(1):12-6. Available from URL: http://www.scielo.br/aob.

\section{INTRODUCTION}

Unicompartmental knee arthroplasty (UKA) seems an appropriate procedure for treating spontaneous osteonecrosis of the knee
(SONK) with unaffected lateral and patellofemoral compartments. Less invasive than other surgical procedures and with positive clinical outcomes, UKA replaces only the affected condyle and

All authors declare no potential conflict of interest related to this article.

The study was conducted at Department of Orthopedic Surgery and Joint Surgery Center, Takatsuki General Hospital. Correspondence: Tomoyuki Kamenaga, 1-3-13, Kosobe-cho, Takatsuki, Osaka 569-1192, Japan. t.kamenaga@gmail.com 
preserves all major ligaments, including the anterior cruciate ligament (ACL). ${ }^{1-5}$ However, a recent systematic review on the use of UKA for the treatment of SONK verified a wide variation in survival rates within the literature, stressing the importance of appropriately selecting patients. ${ }^{6}$

Despite extensive knowledge on SONK affecting the femoral condyle, studies approaching SONK in the tibial plateau are still scarce due to its lower prevalence when compared to the femoral component, comprising only approximately $2 \%$ of the cases. ${ }^{7}$ Recent studies found tibial component aseptic mechanical loosening and subsidence to be the leading causes of UKA failure ${ }^{8-10}$ A recent research reported the use of Oxford UKA for the treatment of medial tibial plateau osteonecrosis to achieve positive clinical outcomes. ${ }^{11}$ However, we found no reports in the literature comparing UKA outcomes for SONK affecting the femoral condyle and the tibial plateau due to the major difference in their incidences. Our hypothesis is that the presence of lesion on the tibial component, verified by preoperative magnetic resonance imaging (MRI), can affect UKA clinical and radiographic outcomes for SONK treatment.

This study sought to observe the short and midterm clinical outcomes of mobile-bearing Oxford UKA for treating SONK and determine whether the presence of tibial lesions in preoperative $\mathrm{MRI}$ would affect the clinical and radiographic outcomes of the procedure.

\section{MATERIALS AND METHODS}

\section{Subjects, clinical data, and surgery}

The study protocol was approved by the Ethics Committee of our hospital (No. 2018-79). All patients included in this study signed an informed consent form. Our study group comprised 60 patients diagnosed with SONK affecting the medial femoral condyle, treated in our hospital between 2012 and 2014 with UKA using an Oxford mobile-bearing knee implant (The Oxford Partial Knee, Zimmer Biomet Ltd), and followed up for at least 3 years after surgery. In case of persistent pain and joint collapse with failure of conservative treatment after at least 3 months, surgical treatment was performed. Patients without multicompartment necrotizing involvement, soft tissue imbalance, ligament involvement, and coronal malalignment greater than $15^{\circ}$ underwent UKA. Patients whose outcomes, radiographic evaluation, and knee condition could be measured at the outpatient clinic during the final follow-up were included in the study. Exclusion criteria were knees with fixed flexion greater than $15^{\circ}$, active knee joint infection, and bilateral UKA. Among the 60 patients that participated in the study, 47 were women and 13 men (mean age, $73.1 \pm 6.6$ years; body mass index, $23.1 \pm 3.6 \mathrm{~kg} / \mathrm{m}^{2}$ ) (Table 1).

Among patients, the average preoperative coronal plane alignment on standard weight-bearing anteroposterior (AP) radiographs was $7.4^{\circ} \pm 5.1^{\circ}$ in varus. All surgeries were performed by the senior author $(\mathrm{TH})$ or by surgeons directly instructed by him.

Surgical procedures were conducted as described in the literature.12 Before performing UKA, all intact cruciate ligaments and healthy cartilage in unaffected compartments were confirmed. Cemented implants were used in both tibial and femoral sides for all cases. Osteonecrotic lesion was removed as much as possible so that normal bone could be used as base for cement impregnation while avoiding deeper bone cut, thus prioritizing joint-line preservation and soft tissue balance over complete removal of necrotic lesion. After bone cut, eventual large craters were filled with autologous bone graft, harvested from the bone removed during surgery according to a previously reported method. ${ }^{2}$
Table 1. Patient demographic data.

\begin{tabular}{|c|c|c|c|}
\hline & Group F (N=34) & Group $\mathrm{T}(\mathrm{N}=26)$ & p-value \\
\hline \multicolumn{4}{|l|}{ OKS } \\
\hline preoperatively & $23.4 \pm 9.2$ & $22.8 \pm 9.4$ & 0.65 \\
\hline final follow-up & $37.8 \pm 8.8$ & $38.3 \pm 9.1$ & 0.76 \\
\hline improvement & $14.4 \pm 6.7$ & $15.5 \pm 6.1$ & 0.51 \\
\hline \multicolumn{4}{|l|}{ MFA } \\
\hline preoperatively & $109.8 \pm 12.9$ & $107.9 \pm 12.0$ & 0.88 \\
\hline final follow-up & $132.2 \pm 11.5$ & $130.7 \pm 11.9$ & 0.71 \\
\hline improvement & $22.3 \pm 6.1$ & $22.8 \pm 5.7$ & 0.85 \\
\hline \multicolumn{4}{|l|}{ Complications } \\
\hline Superficial infection & 0 & 1 & N.S \\
\hline Deep infection & 1 & 0 & N.S \\
\hline Tibial plateau fracture & 0 & 1 & N.S \\
\hline \multirow[t]{2}{*}{ Revision cases } & 1 & 0 & N.S \\
\hline & Group F (n=34) & Group T (n=26) & p-value \\
\hline Sex & male 8 , female 26 & male 5 , female 21 & NSw \\
\hline Age & $73.4 \pm 6.4$ y.o & $72.7 \pm 7.6$ y.o & $P=0.86$ \\
\hline Body mass index & $22.7 \pm 3.5 \mathrm{~kg} / \mathrm{m}^{2}$ & $23.5 \pm 3.7 \mathrm{~kg} / \mathrm{m}^{2}$ & P-0.42 \\
\hline Varus deformity & $7.6^{\circ} \pm 5.3^{\circ}$ & $7.1^{\circ} \pm 4.7^{\circ}$ & $P=0.77$ \\
\hline Period from onset to surgery & $61.0 \pm 9.8$ weeks & $68.6 \pm 11.1$ weeks & $P=0.66$ \\
\hline Follow-up & $60.5 \pm 9.3$ months & $\begin{array}{c}56.7 \pm 10.4 \\
\text { months }\end{array}$ & $P=0.49$ \\
\hline
\end{tabular}

Group F: necrotic lesion confined to the femur; Group T: necrotic lesion spread to the tibia; N.S: not significant.

\section{Preoperative MRI classification}

Patients were separated into two groups using T1-weighted preoperative magnetic resonance imaging (MRI). Whereas in group $\mathrm{F}$ the necrotic lesion was confined to the femur, in group $T$ it was spread to the tibia (Figure 1).

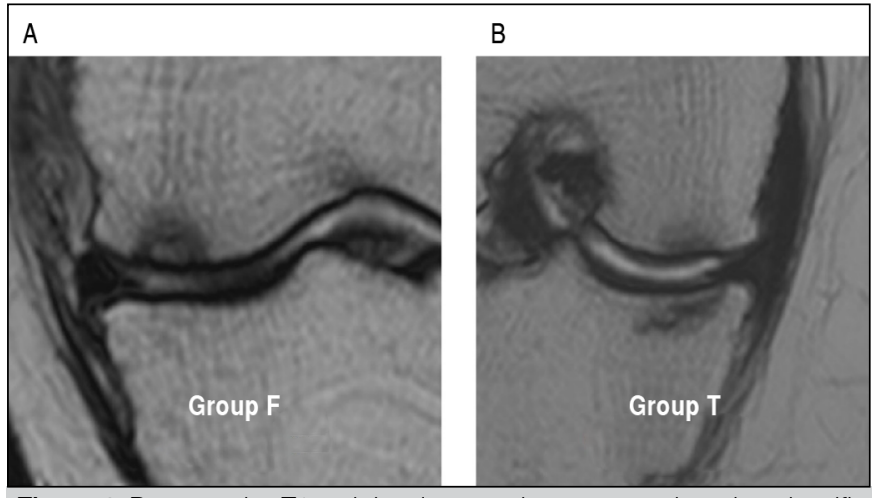

Figure 1. Preoperative T1-weighted magnetic resonance imaging classification. (A): Group F - necrotic lesion confined to the femur; (B) Group Tnecrotic lesion spread to the tibia.

\section{Clinical outcome}

Clinical outcome was measured using the Oxford Knee Score (OKS) - a patient-based questionnaire that allows patients to report functional activity levels and clinical symptoms. OKS has been validated for use in degenerative arthrosis of the $\mathrm{knee}^{2}$ and received a Japanese translation, which was also validated. ${ }^{13}$

The maximum flexion angle (MFA) was measured using a goniometer, both preoperatively and postoperatively (at the final follow-up), to assess clinical outcome.

Both parameters (OKS and MFA) were compared 2 weeks preoperatively and postoperatively (at the final follow-up) using the paired $t$-test $(p<0.05)$. 


\section{Radiolucent line assessment}

Radiolucent line (RLL), that is, the radiolucent interval (measured in millimeters) between the cement and the bone, ${ }^{14}$ was assessed using AP radiography at the final follow-up. Radiolucency was evaluated by adjusting the $\mathrm{X}$-ray beam direction parallel to the tibial component and dividing the bone-cement interface into four zones, according to a previously reported method (Figure 2). ${ }^{15}$

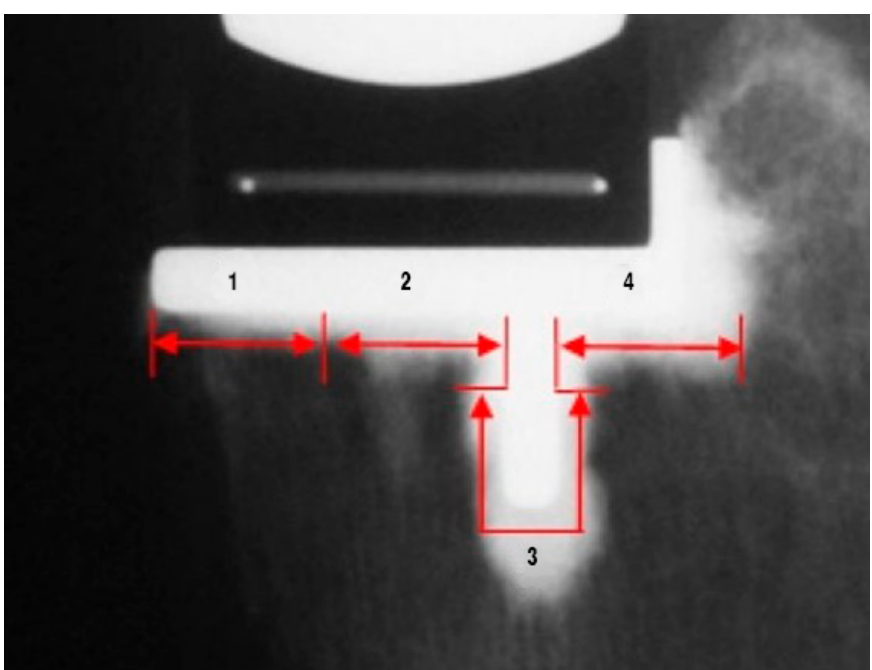

Figure 2. Standardized analysis of the tibial bone-cement interface in four zones, according to a previously reported method.

Those with RLLs in 1-3 zones were considered partial RLL, whereas those with RLLs in all 4 zones were considered completed RLL.

\section{Assessment of tibial component subsidence}

The subsidence of tibial component was evaluated according to changes in radiographic parameters from 2 weeks postoperatively to the final follow-up.

Subsidence distance was measured by the height difference between the center of the lateral compartment and the line in contact with the tibial prosthesis lower surface at 2 weeks postoperatively and at the final follow-up. Subsidence angle was measured by the angular difference between the lateral compartment and the line in contact with the tibial prosthesis lower surface at 2 weeks postoperatively and final follow-up (Figure 3).

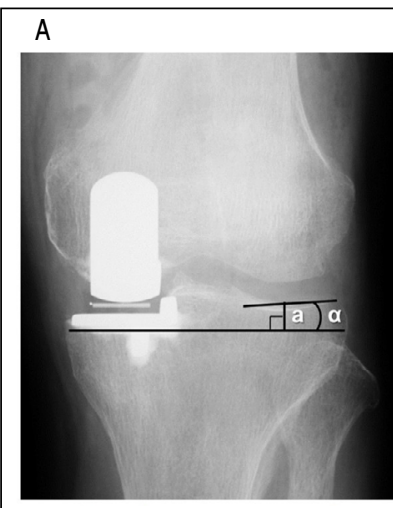

2weeks postoperatively

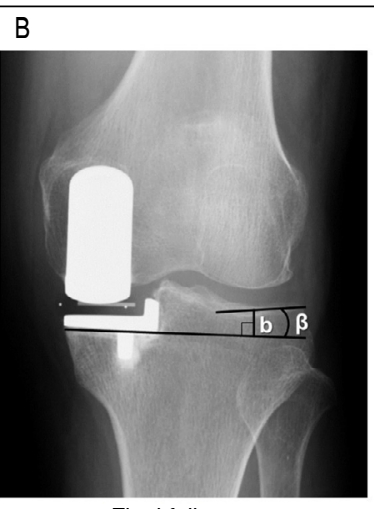

Final follow up
Figure 3. Assessment of tibial component subsidence. The subsidence of the tibial component was evaluated according to changes in radiographic parameters from 2 weeks postoperatively (A); to final follow-up (B) Subsidence distance $(\mathrm{mm})=\mathrm{b}-\mathrm{a}$. Subsidence angle $\left(^{\circ}\right)=\beta-\mathrm{a}$.

\section{Statistical analysis}

Results were analyzed using StatView 5.0 (Abacus Concepts Inc., CA, USA). RLL ratios between the groups were compared using Pearson's chi-square test $(p<0.05)$. Clinical outcome (OKS and MFA) and subsidence (distance and angle) at the final follow- were also compared using unpaired $t$-test $(p<0.05)$. All values are presented as mean \pm standard deviation (SD).

Considering a prespecified significance level at $a<0.05$ and assuming a medium effect size (effect size $=0.5$ ) using G power 3 , the statistical power analysis performed before the study expected a 0.8 power. $^{16}$ The estimated sample size was 54 patients, and $p<0.05$ was considered statistically significant.

\section{RESULTS}

\section{Clinical data}

Table 2 shows the clinical data of both groups (group $F, n=32$; group $T, n=28$ ). We found no significant differences regarding age, sex, body mass index (BMI), and follow-up period between groups.

\begin{tabular}{|c|c|c|c|}
\hline & Group F (N=34) & Group $T(N=26)$ & p-value \\
\hline \multicolumn{4}{|l|}{ OKS } \\
\hline preoperatively & $23.4 \pm 9.2$ & $22.8 \pm 9.4$ & 0.65 \\
\hline final follow-up & $37.8 \pm 8.8$ & $38.3 \pm 9.1$ & 0.76 \\
\hline improvement & $14.4 \pm 6.7$ & $15.5 \pm 6.1$ & 0.51 \\
\hline \multicolumn{4}{|l|}{ MFA } \\
\hline preoperatively & $109.8 \pm 12.9$ & $107.9 \pm 12.0$ & 0.88 \\
\hline final follow-up & $132.2 \pm 11.5$ & $130.7 \pm 11.9$ & 0.71 \\
\hline improvement & $22.3 \pm 6.1$ & $22.8 \pm 5.7$ & 0.85 \\
\hline \multicolumn{4}{|l|}{ Complications } \\
\hline Superficial infection & 0 & 1 & N.S \\
\hline Deep infection & 1 & 0 & N.S \\
\hline Tibial plateau fracture & 0 & 1 & N.S \\
\hline Revision cases & 1 & 0 & N.S \\
\hline
\end{tabular}

Group F: necrotic lesion confined to the femur; Group T: necrotic lesion spread to the tibia; OKS: Oxford knee score; MFA: Maximum flexion angle; N.S: not significant.

\section{Clinical outcome}

OKS and MFA significantly improved in both groups from preoperative to final follow-up, according to paired $t$-test. However, we verified no significant differences between both groups.

\section{Radiographic evaluation (radiolucent line and subsidence)}

Table 3 shows radiographic evaluation results. Radiolucent line $(\mathrm{RLL})$ ratios, partial $\mathrm{RLL}$, and complete $\mathrm{RLL}$ were not significantly different between groups. Group T shows slightly larger subsidence distance and angle than Group F, but without significant differences.

Table 3. Radiographic evaluation for both groups.

\begin{tabular}{c|c|c|c}
\hline & Group F (N=34) & Group T (N=26) & p-value \\
\hline RLL & & & \\
\hline No RLL & $18 / 34(52.9 \%)$ & $14 / 26(53.8 \%)$ & 0.79 \\
\hline Partial RLL & $8 / 34(23.5 \%)$ & $7 / 26(26.9 \%)$ & 0.53 \\
\hline Completed RLL & $6 / 34(17.6 \%)$ & $4 / 26(15.3 \%)$ & 0.55 \\
\hline Subsidence & & & \\
\hline Subsidence distance $(\mathrm{mm})$ & $0.98 \pm 0.08$ & $1.09 \pm 0.10$ & 0.28 \\
\hline Subsidence angle $\left(^{\circ}\right)$ & $0.85 \pm 0.11$ & $1.01 \pm 0.12$ & 0.24 \\
\hline
\end{tabular}

Group F: necrotic lesion confined to the femur; Group T: necrotic lesion spread to the tibia RLL: radiolucent line. 


\section{DISCUSSION}

Oxford mobile-bearing unicompartmental knee arthroplasty (UKA) seems an appropriate procedure to treat spontaneous osteonecrosis of the knee (SONK) regardless of the presence of necrotic lesion on the tibial side besides the femoral side, verified by preoperative magnetic resonance imaging (MRI). To the best of our knowledge, this is the first study to describe the midterm clinical and radiographic outcomes of Oxford UKA in Japanese populations, as well as the impact of tibial lesion on clinical outcomes.

Several authors reported positive midterm outcomes of Oxford mobile-bearing UKA for SONK treatment. A study conducted by Langdown et al. ${ }^{2}$ with 29 patients reported a 100\% survival rate at a mean follow-up of 5 years. Guo et al. ${ }^{17}$ and Zhang et al. ${ }^{18}$ also verified a $100 \%$ survival rate at short follow-up using a minimally invasive approach. In our study, the survival rate was $96.7 \%$, showing that Oxford medial UKA is an effective technique for the treatment of Japanese patients with SONK in the short and midterm. Despite the positive results, further studies should continue to pursue long-term follow-up, given that several studies conducted with follow-up of over 10 years reported a slightly high revision rate, of approximately $10 \% .^{19,20}$

To the detriment of plain radiographs, MRI provides more detailed information for SONK evaluation. Early-stage SONK shows low signal intensity at T1-weighted images, but subchondral areas with high-intensity signals surrounded by low-intensity band-like signals at T2-weighted imaging. ${ }^{21,22}$ In this study, we compared the clinical and radiographic outcomes verified by preoperative T1-weighed MRI of two groups: one with condylar necrosis localized on the femoral side (Group F) and one with lesion spreading on the tibial side (Group T). According to the literature, lesions at the femoral condyle and tibial plateau (Group T) co-occur in around $30-40 \%$ of all SONK patients ${ }^{7,23,24}$ following two patterns. The first occurs in SONK natural course in the femoral condyle, as explained by Koshino et al. ${ }^{25}$ After osteonecrosis onset in the femoral condyle with a typical oval shadow in the subchondral area at the weight-bearing portion, the shadow expands and a surrounding sclerotic halo is formed. Then, these changes lead to ipsilateral lesions of the subchondral bone and articular cartilage in tibial plateau and consequently to osteoarthritis $(\mathrm{OA})$ progression, including osteophytes, osteosclerosis, and joint-space narrowing. The second pattern refers to the occurrence after minor trauma, such as meniscal injury. Mechanical environmental changes after medial meniscus injury may increase contact stresses across the joint, resulting in focal subchondral overload and fracture, and possibly leading to osteonecrosis development on both the femur and tibial side simultaneously. ${ }^{26-28}$ Still regarding UKA for Group T, surgeons should also be concerned about tibial component loosening caused by incomplete seating due to poor bone quality, given that aseptic tibial component loosening was reported as the leading cause of failure in medial UKA. ${ }^{8,29}$ We found no significant differences in the clinical and radiographic evaluations between groups $F$ and $T$, suggesting that the presence of necrotic lesion on the tibial plateau in preoperative MRI should not be considered a contraindication for the use of medial UKA for the treatment of SONK. We found no reports in the literature correlating clinical outcome to the extent of the surrounding bone marrow lesions after medial UKA. ${ }^{30}$ Yet, to our best knowledge, this is the first study to describe the minimal influence of tibial plateau lesion in preoperative MRI on clinical and radiographic outcomes after the use of Oxford UKA for treating SONK affecting the femoral condyle.

Our study had some limitations, such as the limited sample size and short follow-up period, indicating the need for further longterm research with larger sample size. We also did not perform a histological examination of osteonecrosis, which would be important for differentiate osteonecrosis from insufficiency fracture. Moreover, imaging results are influenced by the onset period in view of its diversity until MRI evaluation. Regardless of the limitations, this study suggests that the presence of tibial side lesions in preoperative MRI is not a predictor of poor outcome in the use of UKA for SONK.

\section{CONCLUSION}

The Oxford medial UKA is a reliable option for treating SONK in the short and midterm. The presence of lesions spread to the tibia in preoperative $\mathrm{MRI}$ does not affect the procedure radiographic and clinical outcomes.

AUTHORS' CONTRIBUTIONS: Each author contributed individually and significantly to the development of this article. TK: writing of the original draft, formal analysis, investigation; TH: conceptualization, supervision, review, editing; YH: data curation, review, editing.; TF: data curation, review, editing; KO: data curation, review and editing.

\section{REFERENCES}

1. Marmor L. Unicompartmental arthroplasty for osteonecrosis of the knee joint. Clin Orthop Relat Res. 1993;(294):247-53.

2. Langdown AJ, Pandit H, Price AJ, Dodd CA, Murray DW, Svard UC, et al. Oxford medial unicompartmental arthroplasty for focal spontaneous osteonecrosis of the knee. Acta Orthop. 2005;76(5):688-92.

3. Fukuoka S, Fukunaga K, Taniura K, Sasaki T, Takaoka K. Medium-term clinical results of unicompartmental knee arthroplasty for the treatment for spontaneous osteonecrosis of the knee with four to 15 years of follow up. The Knee. 2019;26(5):1111-16.

4. Ollivier M, Jacquet C, Lucet A, Parratte S, Argenson JN. Long-Term Results of Medial Unicompartmental Knee Arthroplasty for Knee Avascular Necrosis. J Arthroplasty. 2019;34(3):465-8.

5. Kaneko T, Kono N, Sunakawa T, Okuno Y, Ikegami H, Musha Y. Reliable patient-reported outcome measure and survivorship of UKA for primary spontaneous osteonecrosis. Eur J Orthop Surg Traumatol. 2019;29(1):119-24.

6. Myers TG, Cui Q, Kuskowski M, Mihalko WM, Saleh KJ. Outcomes of total and unicompartmental knee arthroplasty for secondary and spontaneous osteonecrosis of the knee. J Bone Joint Surg Am. 2006;88:76-82.

7. Carpintero P, Leon F, Zafra M, Montero R, Carreto A. Spontaneous collapse of the tibial plateau: radiological staging. Skeletal Radiol. 2005;34(7):399-404.

8. Collier MB, Eickmann TH, Sukezaki F, McAuley JP, Engh GA. Patient, implant, and alignment factors associated with revision of medial compartment unicondylar arthroplasty. J Arthroplasty. 2006;21(6 Suppl 2):108-15.
9. Scott CEH, Powell-Bowns MFR, MacDonald DJ, Simpson PM, Wade FA. Revision of Unicompartmental to Total Knee Arthroplasty: Does the Unicompartmental Implant (Metal-Backed vs All-Polyethylene) Impact the Total Knee Arthroplasty? J Arthroplasty. 2018;33(7):2203-9.

10. Lewis PL, Davidson DC, Graves SE, Steiger RN, Donnelly W, Cuthbert A. Unicompartmental Knee Arthroplasty Revision to TKA: Are Tibial Stems and Augments Associated With Improved Survivorship? Clin Orthop Relat Res. 2018;476(4):854-62.

11. Kamenaga T, Hiranaka T, Hida Y, Fujishiro T, Okamoto K. Unicompartmental knee arthroplasty for spontaneous osteonecrosis of the medial tibial plateau. Knee. 2018;25(4):715-21.

12. Pandit H, Jenkins C, Barker K, Dodd CA, Murray DW. The Oxford medial unicompartmental knee replacement using a minimally-invasive approach J Bone Joint Surg Br. 2006;88(1):54-60.

13. Takeuchi R, Sawaguchi T, Nakamura N, Ishikawa H, Saito T, Goldhahn S. Cross-cultural adaptation and validation of the Oxford 12 - item knee score in Japanese. Arch Orthop Trauma Surg. 2011;131(2):247-54.

14. Ritter MA, Herbst SA, Keating EM, Faris PM. Radiolucency at the bone-cement interface in total knee replacement. The effects of bone - surface preparation and cement technique. J Bone Joint Surg Am. 1994;76(1):60-5.

15. Clarius M, Hauck C, Seeger JB, James A, Murray DW, Aldinger PR. Pulsed lavage reduces the incidence of radiolucent lines under the tibial tray of Oxford 
unicompartmental knee arthroplasty: pulsed lavage versus syringe lavage. Int Orthop. 2009;33(6):1585-90

16. Faul F, Erdfelder E, Buchner A, Lang AG. Statistical power analyses using G*Power 3.1: tests for correlation and regression analyses. Behav Res Methods. 2009;41(4):1149-60.

17. Guo WS, Zhang QD, Liu ZH, Cheng LM, Yue DB, Wang WG, et al. Minimally invasive unicompartmental knee arthroplasty for spontaneous osteonecrosis of the knee. Orthop Surg. 2015;7(2):119-24.

18. Zhang Q, Guo W, Liu Z, Cheng L, Yue D, Zhang N. Minimally invasive unicompartmental knee arthroplasty in treatment of osteonecrosis versus osteoarthritis: a matched-pair comparison. Acta Orthop Belg. 2015;81(2):333-9

19. Bruni D, lacono F, Raspugli G, Zaffagnini S, Marcacci M. Is unicompartmental arthroplasty an acceptable option for spontaneous osteonecrosis of the knee? Clin Orthop Relat Res. 2012;470(5):1442-51.

20. Heyse TJ, Khefacha A, Fuchs-Winkelmann S, Cartier P. UKA after spontaneous osteonecrosis of the knee: a retrospective analysis. Arch Orthop Trauma Surg. 2011;131(5):613-7.

21. Bjorkengren AG, AIRowaih A, Lindstrand A, Wingstrand $H$, Thorngren $K G$, Pettersson $\mathrm{H}$. Spontaneous osteonecrosis of the knee: value of MR imaging in determining prognosis. AJR Am J Roentgenol. 1990;154(2):331-6.

22. Pollack MS, Dalinka MK, Kressel HY, Lotke PA, Spritzer CE. Magnetic resonance imaging in the evaluation of suspected osteonecrosis of the knee. Skeletal Radiol. 1987;16(2):121-7.
23. Houpt JB, Alpert B, Lotem M, Greyson ND, Pritzker KP, Langer F, et al. Spontaneous osteonecrosis of the medial tibial plateau. J Rheumatol. 1982;9(1):81-90.

24. Narvaez JA, Narvaez J, De Lama E, Sanchez A. Spontaneous osteonecrosis of the knee associated with tibial plateau and femoral condyle insufficiency stress fracture. Eur Radiol. 2003;13(8):1843-8.

25. Koshino T. The treatment of spontaneous osteonecrosis of the knee by high tibial osteotomy with and without bone-grafting or drilling of the lesion. J Bone Joint Surg Am. 1982;64(1):47-58.

26. Krause WR, Pope MH, Johnson RJ, Wilder DG. Mechanical changes in the knee after meniscectomy. J Bone Joint Surg Am. 1976;58(5):599-604.

27. Yao L, Stanczak J, Boutin RD. Presumptive subarticular stress reactions of the knee: MRI detection and association with meniscal tear patterns. Skeletal Radiol. 2004;33(5):260-4

28. Yang WM, Zhao CQ, Lu ZY, Yang WY, Lin DK, Cao XW. Clinical Characteristics and Treatment of Spontaneous Osteonecrosis of Medial Tibial Plateau: A Retrospective Case Study. Chin Med J (Engl). 2018;131(21):2544-50.

29. Aleto TJ, Berend ME, Ritter MA, Faris PM, Meneghini RM. Early failure of unicompartmental knee arthroplasty leading to revision. J Arthroplasty. 2008;23(2):159-63

30. Jacobs CA, Berend KR, Lombardi AV Jr, Christensen CP. The Location and Severity of Preoperative Subchondral Bone Marrow Lesions Were Not Associated With Inferior Postoperative Outcomes After Medial Unicompartmental Knee Arthroplasty or Total Knee Arthroplasty. J Arthroplasty. 2016;31(11):2476-80. 